Meta

Journal des tradlucteurs

Translators' Journal

\title{
Une sécurité aux huit visages
}

\section{Robert Dubuc}

Volume 17, numéro 3, septembre 1972

URI : https://id.erudit.org/iderudit/002595ar

DOI : https://doi.org/10.7202/002595ar

Aller au sommaire du numéro

Éditeur(s)

Les Presses de l'Université de Montréal

ISSN

0026-0452 (imprimé)

1492-1421 (numérique)

Découvrir la revue

Citer cet article

Dubuc, R. (1972). Une sécurité aux huit visages. Meta, 17(3), 165-167.

https://doi.org/10.7202/002595ar

Ce document est protégé par la loi sur le droit d'auteur. L’utilisation des services d'Érudit (y compris la reproduction) est assujettie à sa politique d'utilisation que vous pouvez consulter en ligne.

https://apropos.erudit.org/fr/usagers/politique-dutilisation/
Cet article est diffusé et préservé par Érudit.

Érudit est un consortium interuniversitaire sans but lucratif composé de l’Université de Montréal, l'Université Laval et l'Université du Québec à Montréal. Il a pour mission la promotion et la valorisation de la recherche. https://www.erudit.org/fr/ 


\section{PROBLÈMES ET SOLUTIONS}

\section{UNE SÉCURITÉ AUX HUTT VISAGES}

La recherche de la sécurité est devenue peut-être la préoccupation fondamentale de l'homme d'aujourd'hui. C'est sans doute pour lui une façon de pallier son insécurité profonde. Ainsi la recherche de la sécurité a marqué très tôt l'activité syndicale, si bien qu'on ne saurait traiter tant soit peu sérieusement de terminologie syndicale sans aborder les termes relatifs à la sécurité syndicale (union security).

On regroupe sous cette étiquette un ensemble de mesures destinées à garantir le maintien d'un syndicat au sein d'une entreprise. Elles se traduisent en général par la protection de l'affiliation syndicale (union membership), c'est-à-dire que le syndicat bénéficie d'un certain appui pour maintenir ses effectifs à un niveau satisfaisant.

Dans l'entreprise nord-américaine, on peut ramener à huit types fondamentaux ${ }^{1}$ les régimes de sécurité syndicale en vigueur. Ils représentent à peu près tous les degrés de sécurité.

Au point de sécurité zéro, on trouve le régime dit de l'atelier antisyndical (anti-union shop). Il s'agit de la négation pure et simple du syndicalisme. L'engagement de syndiqués est automatiquement exclu ; il n'est pas question de reconnaître un syndicat et encore moins de négocier les conditions de travail.

Dès le départ, se pose le problème de la traduction du mot shop, qui figure dans la majorité des appellations des régimes de sécurité syndicale. Ce mot a été généralement traduit par atelier. Même si l'orthodoxie de cette traduction peut paraître douteuse, cet usage a pris une ampleur telle qu'il s'est imposé. Des expressions comme «atelier antisyndical, atelier fermé, atelier ouvert ou libre, atelier

1. Dale Yoder, Personnel Management and Industrial Relations, 5e éd., Englewood Cliffs (N.J.), Prentice-Hall Inc., 1962, p. 189. 
syndiqué » semblent avoir pris pied bien au-delà de nos frontières ${ }^{2}$ et l'on peut se demander à bon droit s'il y a lieu de ramer à contre-courant.

On peut donc ainsi, sans trop se torturer la conscience, parler d'atelier fermé (closed shop) pour désigner cette espèce de monopole accordé au syndicat pour le recrutement de la main-d'œuvre. Sous ce régime, en effet, c'est le syndicat qui fournit toute la main-d'œuvre et personne ne peut être engagé s'il n'est pas d'abord syndiqué (union member).

Ce régime à domination syndicale totale s'oppose à ce qu'on appelle de façon un peu servile l'atelier ouvert ou mieux l'atelier libre (open shop). C'est pour ainsi dire un régime à sécurité minimale pour le syndicat. L'adhésion au syndicat est tolérée, mais le syndicat lui-même ne bénéficie d'aucune reconnaissance et n'est partie à aucune convention.

On comprend que les syndicats ne soient pas particulièrement friands d'un tel régime et qu'ils cherchent au moins à se faire reconnaître comme agent négociateur. C'est fondamentalement cette reconnaissance que leur accorde le régime d'exclusivité syndicale (exclusive bargaining agent). Ici l'adhésion au syndicat est facultative, mais le syndicat est reconnu comme l'agent négociateur exclusif de tous les salariés, syndiqués ou non.

Pour éviter que la responsabilité du syndicat soit trop lourde en regard 'du nombre de ses adhérents, certaines entreprises accordent au syndicat un régime dit de préférence syndicale (preferential shop). Ce régime donne, au moment de l'engagement, préférence aux syndiqués sur les non-syndiqués.

Mais là encore ce régime n'est pas au gré des syndicats qui trouvent frustrante la présence de resquilleurs ou de parasites (free riders ${ }^{3}$ ), ces salariés non syndiqués qui bénéficient de tous les avantages acquis par le syndicat sans jamais rien verser en retour.

C'est dans l'espoir de remédier à ce mécontentement des syndicats, tout en respectant l'objection de certains patrons à l'adhésion syndicale obligatoire, qu'on a mis au point un régime de compromis appelé cotisation universelle (agency shop), mieux connu au Canada sous le nom de formule Rand (Rand Formula) du nom du juge qui l'a proposée la première fois. Ce régime exige que tous les salariés du groupement signataire versent leurs cotisations au syndicat sans pour autant être tenus d'y adhérer.

Une autre formule de compromis, le maintien d'affiliation (maintenance of membership), ne porte pas sur l'adhésion elle-même, mais sur certaines de ses modalités. À partir d'une date donnée, les salariés doivent adhérer au syndicat pour

2. Glossaire syndical et terminologie des salaires, Washington (D.C.), Service de l'analyse industrielle, Ambassade de France, 155 p.; Glossaire de gestion du personnel, Buenos Aires, Association européenne pour la direction du personnel, 1970, $133 \mathrm{p}$.; Jean Neuville, la Sécurité syndicale, Bruxelles et Paris, Office général du livre, 1957, $96 \mathrm{p}$. Je suis redevable de ces deux dernières références aux étudiants de deuxième année de traduction à l'Université de Montréal.

3. Certains auteurs traduisent littéralement cette expression par «passager non payant ». Il va sans dire que cette traduction n'est pas très satisfaisante. Elle ne rend pas l'aspect péjoratif de la locution américaine. Les équivalents donnés ici, proposés par le Comité de linguistique de Radio-Canada (fiches), semblent en tout point préférables. 
toute la durée de la convention et verser régulièrement leurs cotisations. Toutefois, une clause de désistement (escape clause) permet, dans les dix ou quinze jours suivant la signature de la convention, à ceux qui le désirent de se retirer du syndicat.

Il nous reste à parler du dernier «visage » de la sécurité syndicale, le plus répandu et le mieux connu, le régime de l'atelier syndiqué (union shop). Sous ce régime, l'adhésion au syndicat est obligatoire, mais seulement après le stage ou, comme on dit maintenant en France, la période de probation (probation period).

On peut donc résumer schématiquement ainsi cette petite étude du vocabulaire de la sécurité syndicale :

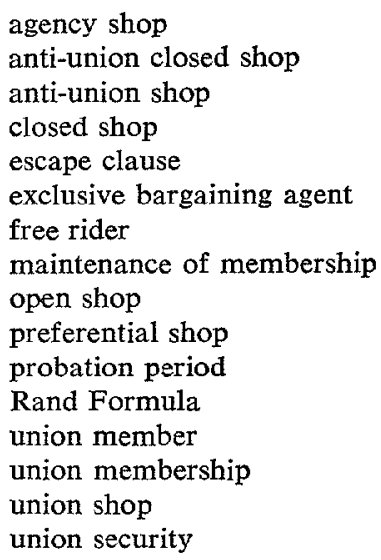

cotisation universelle voir anti-union shop atelier antisyndical atelier fermé clause de désistement exclusivité syndicale resquilleur ; parasite maintien d'affiliation atelier libre ; atelier ouvert préférence syndicale stage; période de probation formule Rand ; cotisation universelle syndiqué affiliation syndicale atelier syndiqué sécurité syndicale 